\title{
Influence of AWJM Parameter on GFRP Reinforced Nylon-6 Composite
}

\author{
Rajesh S, Manivannan J, Chokkalingam R
}

\begin{abstract}
This research article is aiming to comprehend the cause of Abrasive Water Jet Machining (AWJM) parameter on kerf angle of the polymer based composites. Direct extrusion method is adopted to fabricate the Nylon 6 - GFRP composites. $L_{27} \mathrm{OA}$ design is followed to carry out to study the behaviour of AWJM parameter Kerf Angle $\left(K_{a}\right)$. Three parameters with three levels are formulated; the selected parameters are pressure of the jet, standoff distance and feed rate and output is $K_{a}$. Taguchi optimization tool is used to locate the optimal combination of the AWJM parameter. The maximum pressure, low feed rate and standoff distance are the beneficial for reducing the kerf angle. ANOVA is also employed to determine the contribution of each process parameter on kerf angle and it is found that pressure combined with standoff distance plays important role in reducing the $K_{a}$ followed by standoff distance and feed rate.
\end{abstract}

Keywords : Nylon 6, GFRP, AWJM, Kerf angle, Taguchi.

\section{INTRODUCTION}

Glass Fibre Reinforced Plastic (GFRP) materials are extensively used in numerous uses owing to their elevated strength and modulus and added with low specific weight [1]. This property attracts the requirement of aerospace and ship constructional materials. On other side Nylon 6 composites are used extensively in bearings and gear wheels, because of their high temperature stability [2]. Nylon 6 is used as reinforcement and polycaprolactone is used as matrix materials. Compression molding technique is used for the fabrication of Nylon 6 reinforced composites [3]. Nylon 6 is used as reinforced with kenaf fiber and their properties of the composites are studied, it noted that tensile strength of the composites improved marginally [4]. The problem persists with the novel and a new material is forming into the desired shape and size. Parida et al revealed that Abrasive Water Jet Cutting (AWJM) of composite have a number of defy. So, it is essential to build up a method to acclimatize the process

Revised Manuscript Received on December 5, 2019

* Correspondence Author

Rajesh $\mathbf{S}^{*}$, Department of Mechanical Engineering, Kalasalingam Academy of Research and Education, Krishnankoil, India. Email: s.rajesh@klu.ac.in

Manivannan J, Department of Mechanical Engineering, Kalasalingam Academy of Research and Education, Krishnankoil, India. Email: j.manivannan@klu.ac.in

Chokkalingam R, Department of Physics, Kalasalingam Academy of Research and Education, Krishnankoil, India. Email: r.chokkalingam@klu.ac.in parameters for every GFRP material. The reason is machine manufacturers may not have the complete data base for the new/novel materials. The outcome of the study narrated that machinability index of different composite materials is vary and different and it is noted that feed rate important factor which affects the kerf angle of the composites [5]. Palleda conducted the experimentation to learn influence AWJM parameter on two different materials and it is compared with GFRP, based on its kerf angle and material removal rate. Pressure and Standoff Distance are the key factors in affecting the kerf angle and material removal rate [6]. Palanikumar et al studied the influence of AWJM machining parameters on Ra and MRR of GFRP composites using full factorial design. Coated carbide tool is used to perform the experimentation and the most influencing cutting speed, work piece fiber orientation angle, depth of cut and feed rate are selected as control factors. Fiber orientation angle and cutting speed highly influences the Ra and MRR [7]. Libor conducted an experimental study on AWJM by oscillating the nozzle to cut the GFRP composites and a performance is compared with the standard AWJM process. It is noted that oscillating nozzle is capable of producing good surface quality and texture [8]. It is understood from the literature survey there are studies which dealt with GFRP composites, there no or less systematic studies in Nylon 6 reinforced GFRP composites. In this work, an effort is made to studies the machining behaviour of Nylon 6 reinforced composites.

\section{EXPERIMENTAL DETAILS}

\section{A. Materials and Methods}

Nylon 6 and GFRP materials are purchased from Aaravi marketing limited, India. Nylon 6 is purchased in the form of plastic granules and GFRP sheet. GFRP sheet is cut into small pieces equal to the size of Nylon 6 granules. Extrusion process is used to fabricate the required number of composites. APPL plastic extrusion machine with $100 \mathrm{~kW}$ power supply is used to melt and to extrude the specimen with the size of 30X200 mm.

Published By: 


\section{B. Abrasive water jet machining of Nylon 6 reinforced with 15\% GFRP}

To cram the influence of the abrasive water jet machining parameters, the required numbers of nylon 6 reinforced with $15 \%$ GFRP is fabricated through extrusion process. The dimension of the specimen is diameter $30 \mathrm{~mm}$ and $200 \mathrm{~mm}$ in length. The abrasive water jet machining process is conceded through Dardi International. The garnet abrasive particle with 80 micron is used for the cutting the composites. The flow rate of the garnet abrasive particle is maintained constant throughout the cutting process. The cutting length is fixed as $20 \mathrm{~mm}$ for each cut, and the experiments are repeated twice. Fig. 1. shows the experimental setup used for abrasive water jet cutting operation.

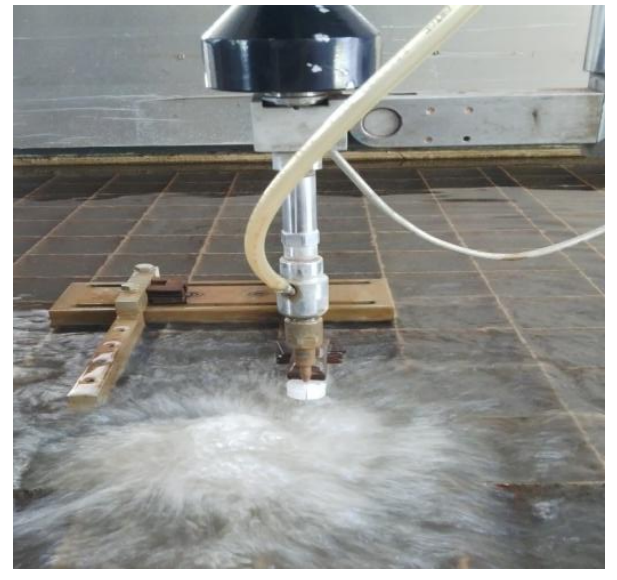

Fig. 1. Abrasive water jet machining of nylon reinforced composites

Kerf angle $\left(\mathrm{K}_{\mathrm{a}}\right)$ is carefully measured with non contacting type optical measurements system. The top and bottom dimension of the cut surface is taken at three positions in entry and exit of the abrasive water jet machined area. The procedure is repeated two times at both position of the machined surface, and the mean values are listed. In this learn, three levels are considered for every process parameter, as given in Table I.

Table- I: Abrasive water parameters and its array

\begin{tabular}{|c|c|c|c|c|}
\hline Parameters & Unit & Level 1 & Level 2 & Level 3 \\
\hline Pressure (P) & $\mathrm{MPa}$ & 144 & 192 & 240 \\
\hline $\begin{array}{c}\text { Standoff Distance } \\
\text { (SoD) }\end{array}$ & $\mathrm{mm}$ & 1 & 2 & 3 \\
\hline Feed Rate (FR) & $\mathrm{mm} / \mathrm{min}$ & 20 & 30 & 40 \\
\hline
\end{tabular}

The parameter levels are selected inside the intervals, based on the specification given by the machine supplier. Three process parameters at three levels directed to a total of 27 examinations. $\mathrm{L}_{27}$ orthogonal array is selected; table has 27 rows equivalent to the number of parameter combinations, with 26 degrees of freedom and 13 columns. The first, second, and eighth columns of the orthogonal array are allocated to the pressure, standoff distance and feed rate.

\section{RESULT AND DISCUSSION}

This section presents the experimental examination of the effect of significant process parameters, such as pressure, standoff distance and feed rate on kerf angle characteristics. The production performance characteristics are kerf angle. Assortment of an appropriate orthogonal array is plays vital responsibility in conducting the trial. Only the main factors are taken into consideration and its interactions. Degree of Freedom (DoF) for each control parameter is two (total number of level - one $=$ two degree of freedom), interaction between the parameter is four and consequently, the total DoF is twenty six. DoF should be more than one or at least equal to the number of experiments. In this case, $\mathrm{L}_{27}$ is selected, therefore DoF is 26. Taguchi technique is utilized to examine the result of the three water jet cutting parameters by reducing the discrepancy on the response, and optimizing the response by computing $\mathrm{S} / \mathrm{N}$ ratio. Abrasive water jet machining parameters such as pressure, standoff distance and feed rate has important role in influencing the $\mathrm{K}_{\mathrm{a}} \cdot \mathrm{K}_{\mathrm{a}}$ values for different pressure, feed rate and standoff distance are given in Table II.

Table- II: Abrasive water jet experimental results

\begin{tabular}{|c|c|c|c|c|}
\hline Ex. No & $\mathbf{P}$ & SoD & FR & $\mathbf{K}_{\mathbf{a}}$ \\
\hline 1 & 144 & 1 & 20 & 0.9034 \\
\hline 2 & 144 & 1 & 30 & 0.5689 \\
\hline 3 & 144 & 1 & 40 & 0.5692 \\
\hline 4 & 144 & 2 & 20 & 0.3348 \\
\hline 5 & 144 & 2 & 30 & 0.7362 \\
\hline 6 & 144 & 2 & 40 & 0.5689 \\
\hline 7 & 144 & 3 & 20 & 0.3348 \\
\hline 8 & 144 & 3 & 30 & 0.5357 \\
\hline 9 & 144 & 3 & 40 & 1.0707 \\
\hline 10 & 192 & 1 & 20 & 0.1673 \\
\hline 11 & 192 & 1 & 30 & 0.1337 \\
\hline 12 & 192 & 1 & 40 & 0.5016 \\
\hline 13 & 192 & 2 & 20 & 0.7697 \\
\hline 14 & 192 & 2 & 30 & 1.0372 \\
\hline 15 & 192 & 2 & 40 & 0.4683 \\
\hline 16 & 192 & 3 & 20 & 0.9034 \\
\hline 17 & 192 & 3 & 30 & 1.4054 \\
\hline 18 & 192 & 3 & 40 & 0.8032 \\
\hline 19 & 240 & 1 & 20 & 0.7697 \\
\hline
\end{tabular}




\begin{tabular}{|c|c|c|c|c|}
\hline 20 & 240 & 1 & 30 & 0.2678 \\
\hline 21 & 240 & 1 & 40 & 0.6021 \\
\hline 22 & 240 & 2 & 20 & 0.2675 \\
\hline 23 & 240 & 2 & 30 & 0.1673 \\
\hline 24 & 240 & 2 & 40 & 0.5018 \\
\hline 25 & 240 & 3 & 20 & 0.2962 \\
\hline 26 & 240 & 3 & 30 & 0.4686 \\
\hline 27 & 240 & 3 & 40 & 0.9003 \\
\hline
\end{tabular}

\begin{tabular}{|c|c|c|c|c|}
240 & 1 & 20 & 3.555 & 2.2736 \\
\hline 240 & 1 & 30 & 3.433 & 11.4438 \\
\hline 240 & 1 & 40 & 3.371 & 4.4066 \\
\hline 240 & 2 & 20 & 3.523 & 11.4535 \\
\hline 240 & 2 & 30 & 2.859 & 15.5301 \\
\hline 240 & 2 & 40 & 3.718 & 5.9894 \\
\hline 240 & 3 & 20 & 3.317 & 10.5683 \\
\hline 240 & 3 & 30 & 3.966 & 6.5840 \\
\hline 240 & 3 & 40 & 4.689 & 0.9123 \\
\hline
\end{tabular}

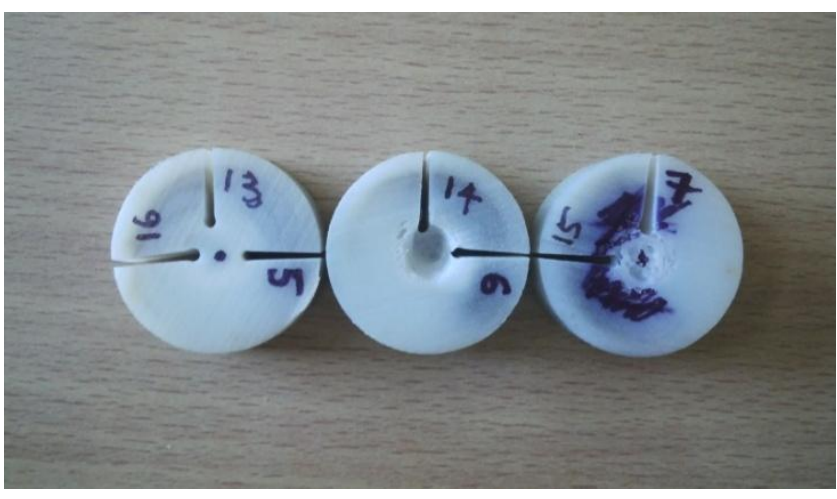

In this effort, it is intended to reduce the $\mathrm{K}_{\mathrm{a}}$ of the machined surface; if the expectation is the lower the better, therefore the following Eqn. 1 is employed to compute the $\mathrm{S} / \mathrm{N}$ ratio for entire experimentation results.

$$
\eta_{\mathrm{ij}}=-10 \log \left(\frac{1}{\mathrm{n}} \sum_{\mathrm{j}=1}^{\mathrm{n}} \mathrm{y}_{\mathrm{ij}}^{2}\right)
$$

The mean $\mathrm{S} / \mathrm{N}$ ratio is computed for entire tests by taking the average of $\mathrm{S} / \mathrm{N}$ ratios for the first level of each parameter. For instance, the mean $\mathrm{S} / \mathrm{N}$ ratio for the first level of pressure is 0.8824 . The mean $\mathrm{S} / \mathrm{N}$ ratio for entire experiments is listed in Table III. The computed $\mathrm{S} / \mathrm{N}$ ratio is shown as a diagram in Fig. 3.

Table- III: S/N Ratio

\begin{tabular}{|c|c|c|c|c|}
\hline $\mathbf{A P}$ & SoD & $\mathbf{T}_{\mathrm{s}}$ & $\mathbf{R}_{\mathbf{a}}$ & S/N Ratio \\
\hline 144 & 1 & 20 & 3.664 & 0.8824 \\
\hline 144 & 1 & 30 & 3.352 & 4.8993 \\
\hline 144 & 1 & 40 & 3.481 & 4.8947 \\
\hline 144 & 2 & 20 & 3.881 & 9.5043 \\
\hline 144 & 2 & 30 & 3.506 & 2.6601 \\
\hline 144 & 2 & 40 & 3.624 & 4.8993 \\
\hline 144 & 3 & 20 & 3.209 & 9.5043 \\
\hline 144 & 3 & 30 & 4.572 & 5.4216 \\
\hline 144 & 3 & 40 & 4.122 & -0.5934 \\
\hline 192 & 1 & 20 & 3.273 & 15.5301 \\
\hline 192 & 1 & 30 & 3.642 & 17.4774 \\
\hline 192 & 1 & 40 & 3.631 & 5.9928 \\
\hline 192 & 2 & 20 & 3.352 & 2.2736 \\
\hline 192 & 2 & 30 & 4.01 & -0.3173 \\
\hline 192 & 2 & 40 & 3.757 & 6.5895 \\
\hline 192 & 3 & 20 & 3.872 & 0.8824 \\
\hline 192 & 3 & 30 & 3.809 & -2.9560 \\
\hline 192 & 3 & 40 & 3.935 & 1.9035 \\
\hline
\end{tabular}

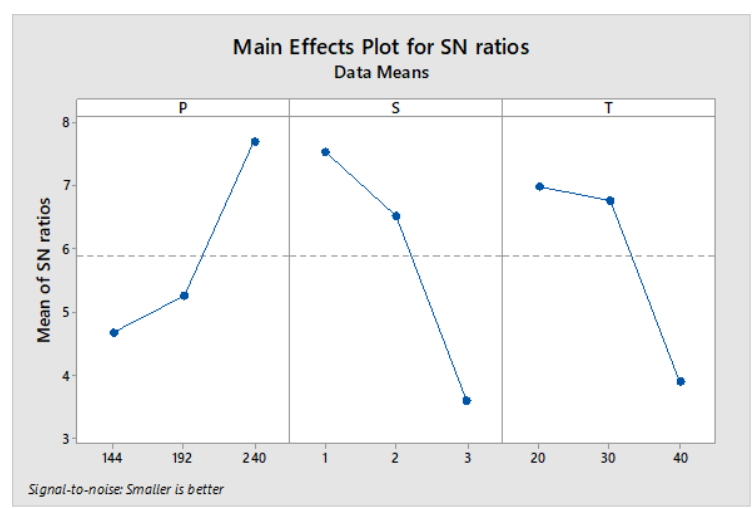

Fig. 3. Means of S/N Ratio

As per the $\mathrm{S} / \mathrm{N}$ ratio values and diagram of the mean $\mathrm{S} / \mathrm{N}$ ratio, the maximum value gives the enhanced performance (minimum kerf angle). Fig. 2 shows the kerf angle of the machined surface at optimal condition. The optimal ideals to minimize the $\mathrm{K}_{\mathrm{a}}$ are established as $\mathrm{A}_{3} \mathrm{~B}_{1}$ and $\mathrm{C}_{1}$ i.e. pressure (240 $\mathrm{MPa})$, standoff distance $(1 \mathrm{~mm})$, and feed rate $(20$ $\mathrm{mm} / \mathrm{sec})$.

Eqns. 2 and 3 are utilized to figure out the Sum of Squares (SS), Variance (V) and contribution of every control parameter. Table IV demonstrate the SS, V and contribution of every control parameter. F test is carried out to study the significance of the process parameter.

Published By:

Blue Eyes Intelligence Engineering 


$$
s s_{j}=\sum_{i=1}^{j}\left(\eta_{j i}-\bar{\eta}\right)^{2}
$$

where $\mathrm{SS}_{\mathrm{j}}$ is the sum of square deviation of the $\mathrm{j}^{\text {th }}$ factor, $\mathrm{i}$ is the level of the $\mathrm{j}^{\mathrm{th}}$ vector.

$$
V_{j}=\frac{S S_{j}}{f_{j}}
$$

$V_{j}$ and $f_{j}$ is the variance and degree of freedom respectively of the $j^{\text {th }}$ factor.

Table- IV: ANOVA for $\mathrm{K}_{\mathrm{a}}$

\begin{tabular}{|c|c|c|c|c|c|}
\hline Parameter & SS & DoF & V & F value & Contribution \\
\hline P & 0.2232 & 2 & 0.1116 & 1.815 & 16.56 \\
\hline SoD & 0.3190 & 2 & 0.1595 & 2.594 & 23.67 \\
\hline FR & 0.0855 & 2 & 0.0427 & 0.695 & 6.34 \\
\hline PXSoD & 0.7354 & 4 & 0.1839 & 2.991 & 27.29 \\
\hline PXFR & 0.3199 & 4 & 0.0800 & 1.301 & 11.87 \\
\hline SoDXFR & 0.3842 & 4 & 0.0961 & 1.562 & 14.26 \\
\hline Error & 0.4918 & 8 & 0.0615 & & \\
\hline
\end{tabular}

The final column of Table IV shows the \% of contribution every of parameter, and its point out the degree of influence on the cutting performance. In this examination, the pressure of the cutting process is extremely important factor, and plays a most important responsibility in affecting the $\mathrm{Ka}$ of the machined surface.

\section{CONCLUSION}

Nylon 6 and GFRP composite successfully fabricated through direct extrusion process. The effect of three process parameter on kerf angle of the composites is studied with $\mathrm{L}_{27}$ orthogonal array. It is found that $\mathrm{A}_{3}, \mathrm{~B}_{1}$ and $\mathrm{C}_{1}$ are the best optimal combination to minimize the kerf angle. ANOVA is also employed, it is found that standoff distance contribute with $23.67 \%$ in affecting the kerf angle followed by feed rate and pressure.

\section{REFERENCES}

1. G. Venu Gopala Rao, Puneet Mahajan, Naresh Bhatnagar, "Three-dimensional macro-mechanical finite element model for machining of unidirectional-fiber reinforced polymer composites", Materials Science and Engineering A 498 (2008) 142-149.

2. Uday K. Vaidya Æ James M. Sands “Thermal stresses in aluminum 6061 and nylon 66 long fiber thermoplastic (LFT) composite joint in a tailcone" Rahul R. Kulkarni Krishan K. Chawla, J Mater Sci (2007) 42:7389-7396

3. R. Palazzetti, A. Zucchelli, I. Trendafilova, The self-reinforcing effect of Nylon 66, nano-fibers on CFRP laminates subjected to low velocity impact", Composite Structures 106 (2013) 661-671.

4. N.Dayananda jawali, Siddeswarappa, Siddaramaiah, Physicomechanical Properties, Machinability, and Morphological Behavior of Short Glass Fiber-reinforced Nylon 6 Composites".

5. Arun kumar Parida, Ratnakar Das, A. K. Sahoo, B. C. Routara "Optimization of cutting parameters for kerf angle in machining of gfrp composites with graphite/fly ash filler" Procedia Materials Science 6 ( 2014 ) 1533 - 1538.
6. Mahabalesh Palleda "A study of taper angles and material removal rates of drilled holes in the abrasive water jet machining process" Journal of Materials Processing Technology 189 (2007) 292-295.

7. K. Palanikumar, L. Karunamoorthy, R. Karthikeyan "Assessment of factors influencing kerf angle on the machining of glass fiber-reinforced polymer composites" Materials and Design 27 (2006) 862-871.

8. Libor M. HlavaC "Investigation of the abrasive water jet trajectory curvature inside the kerf" Journal of Materials Processing Technology 209 (2009) 4154-4161.

\section{AUTHORS PROFILE}

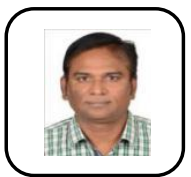

Dr. S. Rajesh completed his B. E in Mechanical Engineering and M.E. ( CAD) from Alagappa Chettiar Government College of Engineering and Technology, Karaikudi, Ph.D (Machining of Metal of Matrix Composites) from Kalasalingam Academy of Research and Education, Krishnankoil in the year 2014, and thesis highly recommended by both the examiners. In the year 2018, I have received DST - AMT project for the worth of Rs. 25,72,400 and completed one IEDC project for the worth of Rs. 1,00,000. He has published more than 25 Journal papers (Impact Factor and Scopus Indexed) and more than 40 International Conference papers.

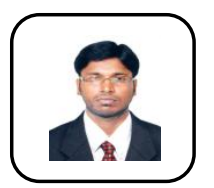

Mr. J. Manivannan completed his B.E. Mechanical Engineering in K.S.Rangasamy College of Technology, Tiruchengode. He has completed his M.Tech (CAD/CAM) in Kalasalingam University, Krishnankoil. He is serving as Assistant Professor in same institute and doing his research as part time mode. His area of research as performance studies on polymer matrix composites. He has published 4 Journal papers (Impact Factor and Scopus Indexed) and more than 15 International Conference papers.

Dr. R. Chokkalingam working as Associate Professor in Department of Physics at Kalasalingam Academy of Research and Education, Krishnankoil. He has published more than 30 Journal papers (Impact Factor and Scopus Indexed) and more than 50 International Conference papers. 